\title{
Effect of craniofacial measures on the cephalic index of Japanese adult female students
}

\author{
Md. Golam Hossain ${ }^{1 *}$, Md. SABIRUZZAman ${ }^{2}$, Saima Islam ${ }^{3}$, Fumio OHTSUki ${ }^{4}$, Pete E. Lestrel ${ }^{5}$ \\ ${ }^{1}$ Department of Orthopaedic Surgery, University of Malaya, Kuala Lumpur 50603, Malaysia \\ ${ }^{2}$ Institute of Mathematical Sciences, University of Malaya, Kuala Lumpur 50603, Malaysia \\ ${ }^{3}$ Department of Statistics, University of Rajshahi, Rajshahi 6205, Bangladesh \\ ${ }^{4}$ Laboratory of Human Biology, Tokyo Metropolitan University, Tokyo 192-0397, Japan \\ ${ }^{5}$ School of Dentistry, University of California at Los Angeles, Los Angeles, CA 90095, USA
}

Received 22 October 2009; accepted 10 November 2009

\begin{abstract}
This study was designed to identify possible craniofacial measurements that have an influence on the cephalic index (CI) of Japanese adult females. The total sample used in the current study consisted of 832 healthy Japanese adults. The subjects were all of Japanese birth and ancestry. The age range of the subjects was between 18-25 years. Eight craniofacial measurements were taken: head length, head breadth, head height, head circumference, minimum frontal breadth, bizygomatic breadth, bigonial breadth, and morphological face height. In addition, stature and body weight were also measured. All measurements were taken by one observer from 1998 to 2001. The CI was calculated from head length and head breadth. Using multiple regression analysis, a variance inflation factor (VIF) demonstrated that there was no evidence of a multicollinearity problem among the variables when CI was considered as a response variable. The coefficients of the regression line demonstrated that there was a significant positive relationship between the CI and minimum frontal breadth $(P<0.01)$, bizygomatic breadth $(P<0.01)$ and head height $(P<0.05)$, while a negative relationship was found between the CI and morphological facial height $(P<0.05)$ and head circumference $(P<0.01)$. Moreover, the coefficient and odds ratio of the logistic regression showed that minimum frontal breadth $(P<0.05)$, bizygomatic breadth $(P<0.01)$, and head height $(P<0.05)$ were more likely in the roundheaded group, while morphological facial height $(P<0.05)$, head circumference $(P<0.01)$, and stature $(P<0.05)$ were less likely in the round-headed group. Stepwise regression analysis showed that with respect to the $\mathrm{CI}$, the best predictor variables were bizygomatic breadth, head circumference, minimum frontal breadth, morphological facial height, head height, and stature. These results suggest that most of the craniofacial variables measured appear to influence the CI of Japanese adult female students.
\end{abstract}

Key words: cephalic index, craniofacial measurements, multiple regression, logistic regression, stepwise regression

\section{Introduction}

The cephalic index $(\mathrm{CI})$ is the ratio of head breadth to head length, i.e. a numeric expression for the relation between the greatest length and the greatest breadth of the cranium. It presumably reflects brain size, i.e. the longest head length defining the greatest anterior-posterior diameter of the cranium and the widest breadth representing the greatest transverse diameter of the cranium. If the cranium is shorter but relatively broader, the head is brachycephalic (roundheaded) and if the cranium is long but relatively narrower, the head is dolichocephalic (long-headed).

Weidenreich (1945) was one of the first researchers to uti-

\footnotetext{
* Correspondence to: Md. Golam Hossain, Department of Orthopaedic Surgery, Faculty of Medicine, University of Malaya, Lembah Pantai, Kuala Lumpur 50603, Malysia.

E-mail: hossain95@yahoo.com

Published online 21 January 2010

in J-STAGE (www.jstage.jst.go.jp) DOI: 10.1537/ase.091022
}

lize the CI. After Weidenreich (1945), many researchers worldwide have described CIs (e.g. Abbie, 1947; Bear, 1956; Roche et al., 1961; Bielicki and Welon, 1964; Huizinga and Slob, 1965; Jorgensen et al., 1974; Skrobak-Kaczynski et al., 1977; Bharati et al., 2001).

In Japan, Suzuki (1956) reported that the medieval Japanese population was long-headed, with a broad face and strong prognathism. After Suzuki (1956), many researchers (e.g. Suzuki, 1967, 1969; Morita and Ohtsuki, 1973; Yanagisawa and Kondo, 1973; Ohtsuki and Ito, 1980; Kouchi, 1986; Kondo et al., 1999; Hossain et al., 2004, 2005) described the Japanese head form using the CI. Some researchers reported that progressive brachycephalization has been present since the Kamakura era (1192-1333), and the rate of increase in the CI of Japanese adults in the last hundred years has been extremely high. Recently, Kouchi (2000) and Hossain et al. $(2004,2005)$ found that the increase in CI in Japanese was mainly affected by the increase of head breadth. CI is a ratio of head breadth and head length; obviously these two measurements are related to CI. 
It is necessary to know which craniofacial measurements (except head breadth and head length) are related to CI. However, our knowledge of the impact of craniofacial measurements on the CI is very limited.

The purpose of the present study was to identify those craniofacial measurements that influence the head form $(\mathrm{CI})$ of Japanese adult female students.

\section{Materials and Methods}

The total sample used in the current study consisted of 832 healthy Japanese adult female students. The subjects were all of Japanese birth and ancestry; their ages at time of measurement were 18-25 years, with an average age of $19.29 \pm 0.98$ years. The measurements were collected from several universities in Tokyo and Kyoto from 1998 to 2001. Various districts of Japan are represented. The craniofacial measurements recorded were: head length, head breadth, head height, head circumference, minimum frontal breadth, bizygomatic breadth, bigonial breadth, and morphological face height; these were all taken by a single observer (F.O.) using the technique of Martin and Saller (1957). In addition, stature and body weight were also measured. The CI was calculated from head breadth and head length:

$$
\left(\mathrm{CI}=\frac{\text { Head breadth }}{\text { Head length }} \times 100\right)
$$

The present sample was subdivided into six groups according to the type of head form: (1) hyper-dolichocephalic (CI $\leq 71.99)$, (2) dolichocephalic $(72.00 \leq \mathrm{CI} \leq 76.99)$, (3) mesocephalic (77.00 $\leq \mathrm{CI} \leq 81.99)$, (4) brachycephalic (82.00 $\leq \mathrm{CI} \leq 86.49)$, (5) hyper-brachycephalic $(86.50 \leq \mathrm{CI} \leq 91.99)$, and (6) ultra-brachycephalic $(\mathrm{CI} \geq 92.00)$ (Table 2).

To examine the average relationship between the CI and the craniofacial measurements, multiple regression analysis was utilized. The underlying multiple linear regression model corresponding to each variable is:

$$
Y=\beta_{0}+\beta_{1} X_{1}+\beta_{2} X_{2}+\beta_{3} X_{3}+\ldots+\beta_{k} X_{k}+\varepsilon
$$

where $Y$ is the response variable $(\mathrm{CI}), X_{i}(i=1,2,3, \ldots, k)$ are the predictor variables (craniofacial measurements), $\beta_{0}$ is the intercept term, $\beta_{1}, \beta_{2}, \ldots, \beta_{k}$ are the unknown regression coefficients, and is the error term with a $N\left(0, \sigma^{2}\right)$ distribution.

In multiple regression analysis, an important assumption is that the explanatory variables are independent of each other, i.e. there is no relationship between the explanatory variables to estimate the ordinary least squares (OLS). However, in some applications of regression, the explanatory variables are related each other. This problem is called the multicollinearity problem (Chatterjee and Hadi, 2006). In this study, a variance inflation factor (VIF) was used to check for the multicollinearity problem among the predictor variables. The variance inflation for independent variables $X_{j}$ is:

$$
\mathrm{VIF}_{\mathrm{j}}=\frac{1}{\left(1-R_{j}^{2}\right)}, \quad j=1,2, \ldots, p
$$

where, $p$ is the number of predictor variables and $R_{j}^{2}$ is the square of the multiple correlation coefficient of the $j$ th variable with the remaining $(p-1)$ variables where:

1) if $0<\mathrm{VIF}<5$, there is no evidence of multicollinearity problem;

2) if $5 \leq \mathrm{VIF} \leq 10$, there is a moderate multicollinearity problem; and

3 ) if VIF $>10$, there is seriously multicollinearity problem of variables.

The present sample was divided into two groups according to roundness of head: (1) long-headed group $(\mathrm{CI} \leq 81.99)$ and (2) round-headed group $(\mathrm{CI} \geq 82.00)$. Roundness of head will be considered as dependent variable and it is categorical; logistic regression was used to find the effect of craniofacial factors on the roundness of head. Finally, stepwise regression was used to choose the most influential craniofacial measures for CI. Stepwise regression is a technique for selecting influential variables in multiple regression models (Chatterjee and Hadi, 2006).

Since CI was derived from head length and head breadth, these two variables were excluded from the analysis in the current study. Statistical analyses were carried out using SPSS software version 15.

\section{Results}

It was necessary first to test the CIs for normality. To check the normality of CIs, the Kolmorov-Smirnov normality test was utilized. The Kolmorov-Smirnov normality test showed that there was no problem concerning the normality of CI, because the $P$-value was greater than 0.05 (Table 1 ).

To examine the linear relationship between the CI and craniofacial measurements, regression coefficients were computed. Coefficients of linear regression showed that the trend of minimum frontal breadth, bizygomatic breadth, and bigonial breadth were significantly positive with the change of head form towards round, while the head circumference showed a negative tendency (Table 2).

\section{Multiple regression analysis}

The multiple regression model used was:

$$
\begin{aligned}
\mathrm{CI}= & \beta_{0}+\beta_{1} \mathrm{MFB}+\beta_{2} \mathrm{BIZB}+\beta_{3} \mathrm{BIGB}+\beta_{4} \mathrm{HHt} \\
& +\beta_{5} \mathrm{MFHt}+\beta_{6} \mathrm{HC}+\beta_{7} \mathrm{St}+\beta_{8} \mathrm{Wt}+\varepsilon
\end{aligned}
$$

where $\mathrm{CI}$ is a response variable and other variables were predictors.

The estimated model was:

$$
\begin{aligned}
\hat{C I}= & 97.9+0.116 \mathrm{MFB}+0.453 \mathrm{BIZB} \\
& +0.0201 \mathrm{BIGB}+0.0562 \mathrm{HHt}-0.0308 \mathrm{MFHt} \\
& -1.55 \mathrm{HC}-0.0531 \mathrm{St}-0.0132 \mathrm{Wt}
\end{aligned}
$$

The regression coefficients and the VIF of the independent variables are presented in Table 3 . The VIF showed that there was no evidence of a multicollinearity problem among the predictor variables. The coefficient of the regression line showed that there was a significant positive association between the CI and minimum frontal breadth $(P<0.01)$, bizygomatic breadth $(P<0.01)$ and head height $(P<0.05)$,

Table 1. Kolmogorov-Smirnov normality test for the CI

\begin{tabular}{cccc} 
Variable & Statistic & df & $P$-value \\
CI & 0.023 & 831 & 0.200 \\
\hline
\end{tabular}


Table 2. Means and standard deviations of craniofacial measurements by the type of head form

\begin{tabular}{|c|c|c|c|c|c|c|c|c|c|c|c|}
\hline \multirow{3}{*}{$n$} & \multirow{2}{*}{\multicolumn{2}{|c|}{$\begin{array}{c}\begin{array}{c}\text { Dolichocephalic } \\
(72.00 \leq \mathrm{CI} \leq 76.99)\end{array} \\
22\end{array}$}} & \multirow{2}{*}{\multicolumn{2}{|c|}{$\begin{array}{c}\begin{array}{c}\text { Mesocephalic } \\
(77.00 \leq \mathrm{CI} \leq 81.99)\end{array} \\
133\end{array}$}} & \multirow{2}{*}{\multicolumn{2}{|c|}{$\begin{array}{c}\begin{array}{c}\text { Brachycephalic } \\
(82.00 \leq \mathrm{CI} \leq 86.49)\end{array} \\
304\end{array}$}} & \multirow{2}{*}{\multicolumn{2}{|c|}{$\begin{array}{l}\text { Hyper brachycephalic } \\
(86.50 \leq \mathrm{CI} \leq 91.99)\end{array}$}} & \multirow{2}{*}{\multicolumn{2}{|c|}{$\begin{array}{l}\text { Ultra brachycephalic } \\
(\mathrm{CI} \geq 92.00) \\
68\end{array}$}} & \multirow[t]{3}{*}{$\begin{array}{l}\text { Regression } \\
\text { Coefficient }^{\mathrm{a}}\end{array}$} \\
\hline & & & & & & & & & & & \\
\hline & Mean & $\mathrm{SD}$ & Mean & $\mathrm{SD}$ & Mean & $\mathrm{SD}$ & Mean & SD & Mean & $\mathrm{SD}$ & \\
\hline MFB & 119.68 & 4.90 & 121.14 & 6.21 & 122.15 & 5.48 & 124.50 & 6.11 & 126.68 & 6.99 & $\begin{array}{r}1.74 * * \\
R^{2}=0.98\end{array}$ \\
\hline BIZB & 133.77 & 5.60 & 136.50 & 4.49 & 137.90 & 4.83 & 139.58 & 4.85 & 141.60 & 4.89 & $\begin{array}{r}1.87 * * \\
R^{2}=0.99\end{array}$ \\
\hline BIGB & 93.86 & 6.88 & 93.29 & 7.97 & 95.22 & 8.90 & 95.01 & 8.31 & 96.90 & 8.59 & $\begin{array}{c}0.78^{*} \\
R^{2}=0.78\end{array}$ \\
\hline $\mathrm{HHt}$ & 133.55 & 7.23 & 129.49 & 6.81 & 129.79 & 5.92 & 129.15 & 6.06 & 129.21 & 6.09 & $\begin{array}{c}-0.90^{\mathrm{ns}} \\
R^{2}=0.58\end{array}$ \\
\hline MFHt & 111.45 & 12.81 & 116.89 & 10.22 & 115.00 & 10.50 & 113.12 & 10.57 & 113.57 & 10.74 & $\begin{array}{c}0.05^{\mathrm{ns}} \\
R^{2}=0.01\end{array}$ \\
\hline $\mathrm{HC}$ & 56.07 & 1.22 & 55.56 & 1.43 & 55.33 & 1.45 & 54.95 & 1.37 & 55.06 & 1.51 & $\begin{array}{c}-0.26^{*} \\
R^{2}=0.87\end{array}$ \\
\hline St & 161.35 & 5.34 & 159.53 & 4.82 & 159.37 & 5.10 & 158.30 & 5.14 & 159.61 & 5.54 & $\begin{array}{c}-0.47^{\mathrm{ns}} \\
R^{2}=0.46\end{array}$ \\
\hline $\mathrm{Wt}$ & 53.34 & 4.92 & 50.59 & 5.26 & 50.88 & 6.00 & 51.13 & 6.18 & 50.96 & 5.90 & $\begin{array}{c}-0.42^{\mathrm{ns}} \\
R^{2}=0.36\end{array}$ \\
\hline
\end{tabular}

MFB, minimum frontal breadth (mm); BIZB, bizygomatic breadth (mm); BIGB, bigonial breadth (mm); HHt, head height (mm); MFHt, morphological face height $(\mathrm{mm})$; HC, head circumference $(\mathrm{cm})$; St, stature $(\mathrm{cm})$; Wt, weight $(\mathrm{kg})$.

${ }^{a}$ Linear trend; $* * 1 \%$ level of significance; $* 5 \%$ level of significance; ns, not significant.

Table 3. Multiple regression coefficients and the VIF for the measurements; CI is the response variable

\begin{tabular}{lcc}
\hline Predictor & Coefficient & VIF \\
\hline MFB & $0.11594^{* *}$ & 1.7 \\
BIZB & $0.45312^{* *}$ & 2.1 \\
BIGB & $0.02008^{\text {ns }}$ & 1.1 \\
HHt & $0.05623^{*}$ & 1.2 \\
MFHt & $-0.03080^{*}$ & 1.1 \\
HC & $-1.5496^{* *}$ & 1.8 \\
St & -0.05305 & 1.4 \\
Wt & -0.01315 & 1.7
\end{tabular}

Same notations as Table 2.

while a negative relationship was found between the CI and morphological facial height $(P<0.05)$, head circumference $(P<0.01)$ and stature $(P<0.10)$.

These results suggest that if an individual has larger minimum frontal breadth, bizygomatic breadth of face and head height, as well as shorter morphological facial height, head circumference and stature, then this also leads to a more rounded head form.

\section{Logistic regression analysis}

Table 4 shows the means and standard deviations for the craniofacial measurements of the long-headed and roundheaded groups. The round-headed group had significantly larger values for minimum frontal breadth, bizygomatic breadth, and bigonial breadth than that of the long-headed group, while the long-headed group had significantly larger values in head circumference, morphological face height, and stature than the round-headed group.

The results of logistic regression analysis are given in Table 5. The coefficients and odds ratio showed that minimum frontal breadth, bizygomatic breadth, and head height were far more likely in the round-headed group, while mor- phological facial height, head circumference, and stature were less likely in the round-headed group.

The odds ratio as well as the regression coefficients explain that, if an individual is round-headed, then the probability of minimum frontal breadth, bizygomatic breadth, and head height would be greater than that for a long-headed person with a probability of $0.043,0.255$, and 0.023 , respectively, while the probability of morphological facial height, head circumference, and stature would be less for the longheaded group with a probability of $0.020,0.549$, and 0.049 , respectively.

\section{Stepwise regression analysis}

The stepwise regression analysis showed that bizygomatic breadth was included in the first step (Table 6). The $R^{2}$ value indicated that there was a $11.33 \%$ reduction in the total variation of the CI due to the predictor variable of bizygomatic breadth. The second step included both the bizygomatic breadth and head circumference. The $R^{2}$ value now indicated a $28.89 \%$ reduction in the total variation of CI due to these two predictor variables. The third step included bizygomatic breadth, head circumference and minimum frontal breadth with the $R^{2}$ value, indicating a $30.31 \%$ reduction in the total variation in the CI due to these three variables. The fourth step included bizygomatic breadth, head circumference, minimum frontal breadth, and morphological face height with an $R^{2}$ demonstrating a $30.84 \%$ reduction in the total variation of the CI due to these four variables. The fifth step included bizygomatic breadth, head circumference, minimum frontal breadth, morphological face height, and head height with coefficient, which led to a $31.30 \%$ reduction in the total variation of the CI, and the final step included bizygomatic breadth, head circumference, minimum frontal breadth, morphological face height, head height, and stature and led to a $31.70 \%$ reduction in the total variation of the CI due to these six variables. The value of Mallows' $C_{p}$ 
Table 4. Means and standard deviations of the craniofacial measurements for the two head form groups

\begin{tabular}{|c|c|c|c|c|c|}
\hline \multirow[t]{2}{*}{ Variables } & \multicolumn{2}{|c|}{ Long-headed (CI $\leq 81.99)$} & \multicolumn{2}{|c|}{ Round-headed (CI $\geq 82.00)$} & \multirow[t]{2}{*}{ Difference } \\
\hline & Mean & SD & Mean & $\mathrm{SD}$ & \\
\hline MFB & 120.94 & 6.05 & 123.66 & 6.11 & $2.72 * *$ \\
\hline BIZB & 136.11 & 4.74 & 139.03 & 4.98 & $2.92 * *$ \\
\hline BIGB & 93.37 & 7.80 & 95.29 & 8.61 & $1.92 *$ \\
\hline $\mathrm{HHt}$ & 130.06 & 6.99 & 129.44 & 5.99 & $-0.62^{\mathrm{ns}}$ \\
\hline MFHt & 116.12 & 10.75 & 114.01 & 10.58 & $-2.11^{*}$ \\
\hline $\mathrm{HC}$ & 55.63 & 1.41 & 55.13 & 1.43 & $-0.40 * *$ \\
\hline St & 159.79 & 4.92 & 158.91 & 5.19 & $-0.88^{*}$ \\
\hline $\mathrm{Wt}$ & 50.98 & 5.28 & 51.00 & 6.06 & $0.02^{\mathrm{ns}}$ \\
\hline
\end{tabular}

Same notations as Table 2 .

Table 5. Logistic regression results of craniofacial measurements on $\mathrm{CI}$

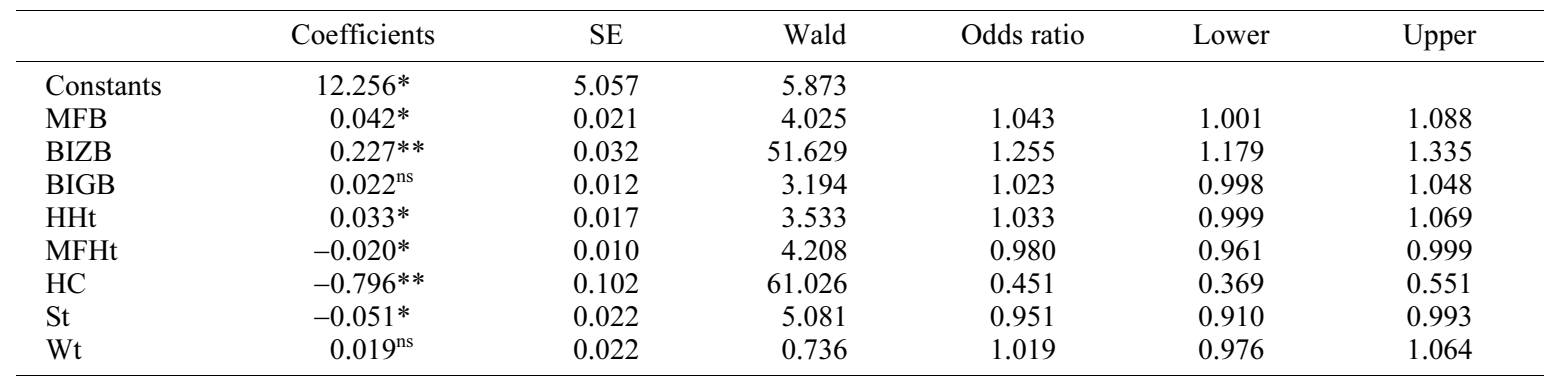

Same notations as Table 2 .

Table 6. Summary of the stepwise regression analysis for craniofacial measurements; CI is the response variable

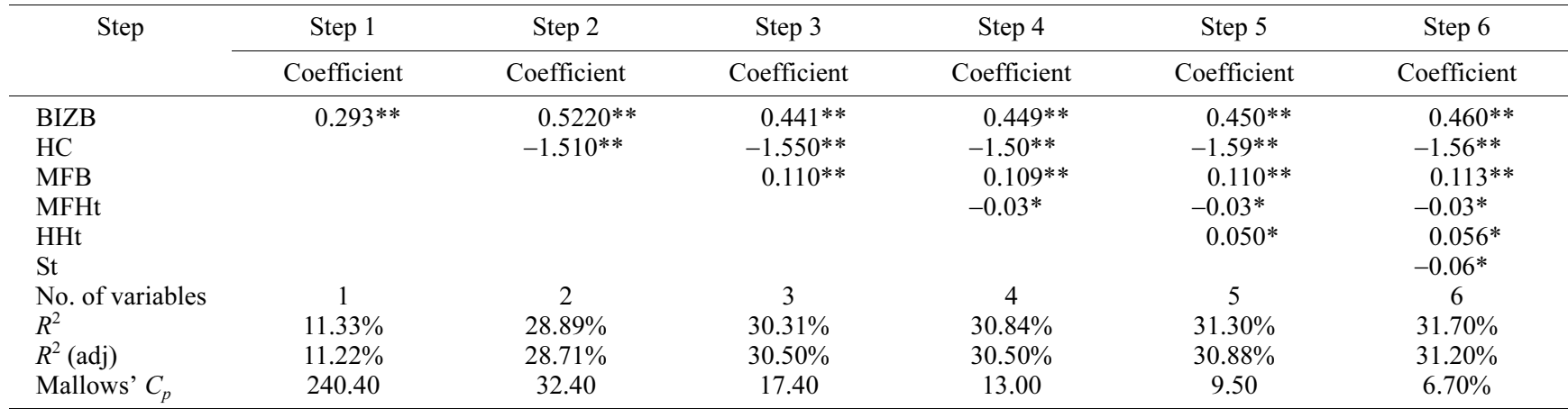

Same notations as Table 2.

decreased with each increment and the smallest value (6.7) was found in the final step.

These results demonstrated that the important craniofacial factors that influenced the CI were bizygomatic breadth, head circumference, minimum frontal breadth, morphological face height, and head height.

\section{Discussion and Conclusions}

Multiple regression analysis, logistic regression analysis, and stepwise regression analysis were used in the present study to identify important craniofacial measurements that influence the head form (CI) of Japanese adult female students. The above statistical analysis demonstrated that most of the craniofacial measurements (except bigonial breadth) were important factors influencing the CI. The coefficients of the regression line verified that there was a positive rela- tionship between the CI and minimum frontal breadth, bizygomatic breadth, and head height, while a negative relationship was found between the CI and morphological facial height, and head circumference. However, the present findings are based on female data. Previous studies (Kouchi, 2000; Hossain et al., 2004, 2005) demonstrated that males and females showed the same tendency of brachycephalization/debrachycephalization in Japan and head breadth was positively associated with CI for both sexes. As far as we know there are no comparable studies available that document the relationship between the CI and craniofacial measurements; consequently, the present findings cannot be compared to other studies.

Previous studies (Hossain et al., 2004, 2005) and others (Ohtsuki and Ito, 1980; Kouchi, 2000) showed that the association of head breadth (positive) and head length (negative) with the CI. Those results suggested that if head breadth 
increases and head length decreases, then the head form (CI) becomes more rounded. As mentioned earlier, in this study we excluded head length and head breadth from the analysis.

The medieval Japanese population was long-headed, with a broad face and strong prognathism (Suzuki, 1967). There is now general agreement that recent Japanese adults are brachycephalic in head form (e.g. Yanagisawa and Kondo, 1973; Ohtsuki and Ito, 1980; Ohtsuki and Iwamura, 1980; Kouchi, 1986, 2000; Nakashima, 1986; Kondo et al., 1999; Hossain et al., 2004, 2005). Suzuki (1969), based on his findings, concluded that the prevailing brachycephalization in the Japanese was due to a decrease in head length and an increase in the head breadth. Ivanovsky (1923) and Suzuki (1948) suggested that the soft-tissue structures overlying the cranial bones have changed in response to better nutritional level over time. This may have differentially affected the soft-tissue component of head breadth more than head length. Evidence remains lacking however.

There have been various other suggestions proposed for possible external and internal factors that have influenced head form (CI). For example, genetics (Abbie, 1947), environmental factors (Abbie, 1947; Beals et al., 1983), protein in the diet (Miller, 1970), psychological and physiological stress (Miller, 1970), medical facilities and care (Miller, 1970), natural climate (Crognier, 1981; Beals et al., 1983; Bharati et al., 2001). Other hypotheses about the factors that are potentially related to head form include heterosis (Billy, 1975), socioeconomic status (Schwidetzky, 1973; Pälsson and Schwidetzky, 1973; Miki, 1990) and nutrition or diet (Lasker, 1946). Some researches (Bielicki and Welon, 1964; Henneberg, 1976) believe that the brachycephalic (rounded) head form has been selected as a consequence of evolutionary forces. Presumably, the answer is multifactorial and a combination of various factors. Clearly, more research is required.

\section{References}

Abbie A.A. (1947) Head form and human evolution. Journal of Anatomy, 81: 233-258.

Beals K.L., Smith C.L., and Dodd S.M. (1983) Climate and the evolution of brachycephalization. American Journal of Physical Anthropology, 62: 425-437.

Bear M.J. (1956) Dimensional changes in the human head and face in the third decade of life. American Journal of Physical Anthropology, 14: 557-576.

Bharati S., Som S., Bharati P., and Vasulu T.S. (2001) Climate and head form in India. American Journal of Human Biology, 13: 626-634.

Bielicki T. and Welon Z. (1964) The operation of natural selection on human head form in an East European population. HOMO, 15: $22-30$

Billy G. (1975) Anthropometric evidence of exogamy related to secular changes in present-day populations. Journal of Human Evolution, 4: 517-520.

Chatterjee S. and Hadi A.S. (2006) Regression Analysis by Example, 4th edn. John Wiley, New York.

Crognier E. (1981) Climate and anthropological variations in Europe and the Mediterranean area. Annals of Human Biology, 8: 99-107.

Henneberg M. (1976) The influence of natural selection on brachycephalization in Poland. Studies in Physical Anthropology, 2: 3-19.

Hossain M.G., Lestrel P.E., and Ohtsuki F. (2004) Secular changes in head dimensions of Japanese females over eight decades.
Anthropological Science, 112: 213-218.

Hossain M.G., Lestrel P.E., and Ohtsuki F. (2005) Secular changes in head dimensions of Japanese adult male students over eight decades. HOMO, 55: 239-250.

Huizinga J. and Slob A. (1965) Progressive brachycephalization: reproduction and head form in the Netherlands. Koninkl Nederl Akademie van Wetterschappen Series C, 8: 297-301.

Ivanovsky A. (1923) Physical modifications of the population of Russia under famine. American Journal of Physical Anthropology, 6: 331-353.

Jorgensen J.B., Drenhause U., and Skrobak-Kaczynski J. (1974) Einige Bemerkungen ueber die Veraenderungen von Koerpermerkmalen bei groenlaendischen Eskimos aus dem noerdlichen Bezirk von Upernavik. Anthropologischer Anzeiger, 34: 89-101.

Kondo S., Wakatsuki E., and Shibagaki H. (1999) A Somatometric study of the head and face in Japanese adolescents. Okajimas Folia Anatomica Japonica, 76: 179-185.

Kouchi M. (1986) Geographic variations in modern Japanese somatometric data: a secular change hypothesis. The University Museum, The University of Tokyo Bulletin, 27: 93-106.

Kouchi M. (2000) Brachycephalization in Japan has ceased. American Journal of Physical Anthropology, 112: 339-347.

Lasker G.W. (1946) Migration and physical differentiation. American Journal of Physical Anthropology, 4: 273-300.

Martin R. and Saller K. (1957) Lehrbuch der Anthroplogie. Bd 1. Gustav Fischer Verlag, Stuttgart.

Miki Z. (1990) Social stratification and the brachycraniazation process in the Medieval period. The Stecci population of Yugoslavia. HOMO, 41: 136-145.

Miller P.S. (1970) Secular changes among the Western Apache. American Journal of Physical Anthropology, 33: 197-206.

Morita S. and Ohtsuki F. (1973) Secular changes of the main head dimensions in Japanese. Human Biology, 45: 151-165.

Nakashima T. (1986) Brachycephalization in the head form of school girls in North Kyushu. Journal of UOEH, 8: 411-414.

Ohtsuki F. and Ito K. (1980) Secular changes in head dimensions among Japanese females. Presented at XI International Congress of Anatomy, 17-23 August 1980, Mexico City (Abstract).

Ohtsuki F. and Iwamura E. (1980) Geographical differences in head and face dimensions among Japanese females. American Journal of Physical Anthropology, 52: 264.

Pälsson J. and Schwidetzky I. (1973) Die variabilitaet anthropologisher merkmale in Island nach Endogamie/Exogamie, Altersklasen und Socialgruppen. HOMO, 24: 23-34.

Roche A.F., Seward F.S., and Sunderland S. (1961) Growth changes in the Mongoloid head. Acta Paediatrica, 50: 133-140.

Schwidetzky I. (1973) Endogamie und anthropologische differenzierung auf den kanarischen inseln. Zeitschrift für Morphologie und Anthropologie, 65: 1-13.

Skrobak-Kaczynski J., Jorgensen J.B., and Drenhaus U. (1977) Secular changes in the Eskimos of the northern district of Upernavik. Journal of Human Evolution, 6: 217-220.

Suzuki H. (1948) On the thickness of soft tissues of the head. Anthropological Science Nippon, 60: 7-11 (in Japanese).

Suzuki H. (1956) Changes in the skull features of the Japanese people from ancient to modern times. In Wallace A.F.C. (ed.), Men and Cultures. University of Pennsylvania Press, Philadelphia, pp. 717-724.

Suzuki H. (1967) Secular changes of the physical characteristics of the Japanese people from the prehistoric to modern times. Kaibogaku Zasshi, 42: 13-15.

Suzuki H. (1969) Microevolutional changes in the Japanese population from the prehistoric age to the present-day. Journal of Faculty of Science, University of Tokyo, Section V 3: 279-309.

Weidenreich F. (1945) The brachycephlization of recent mankind. Southwest Journal of Anthropology, 1: 1-54.

Yanagisawa S. and Kondo S. (1973) Modernization of physical features of the Japanese with special reference to leg length and head form. Journal of Human Ergology (Tokyo), 2: 97-108. 